\title{
A mineração de urânio em questão: análise da comunicação pública das Indústrias Nucleares do Brasil (INB) em Caetité, Bahia
}

\author{
Questioning uranium mining: an analysis of the public communication \\ stated by Indústrias Nucleares do Brasil (INB) in Caetité, Bahia
}

La minería de uranio en cuestión: un análisis de la comunicación pública
transmitida por la INB (Indústrias Nucleares do Brasil) en Caetité, Bahia

Bruno Lucas Saliba de Paula ${ }^{1,2, a}$

bruno.saliba@unimontes.br | https://orcid.org/o0oo-0002-0726-3845

\footnotetext{
${ }^{1}$ Universidade Estadual de Montes Claros, Departamento de Política e Ciências Sociais. Montes Claros, MG, Brasil.

2 Universidade de Brasília, Programa de Pós-Graduação em Sociologia. Brasília, DF, Brasil.

a Mestrado em Sociologia pela Universidade Federal de Minas Gerais.
}

\section{Resumo}

O objetivo deste artigo é discutir, através de análise de conteúdo, as estratégias de comunicação pública adotadas pelas Indústrias Nucleares do Brasil no 'Espaço INB', um centro de informações localizado na cidade baiana de Caetité, onde a empresa realiza a mineração e o beneficiamento de urânio. Desde que foram iniciadas, essas atividades levantaram inúmeras suspeitas de danos ambientais e problemas de saúde pública. Diante disso, buscamos compreender como a INB se posiciona diante dessas suspeitas e se relaciona com as populações atingidas por suas atividades. De acordo com nosso argumento, ao adotar uma postura que denominamos tecnoentusiasta e tecnocrática, a empresa dificulta um debate público aberto e descentralizado sobre as controvérsias em torno da mineração de urânio.

Palavras-chave: Ciência, tecnologia e sociedade; Conflitos socioambientais; Participação pública em ciência e tecnologia; Comunicação pública; Mineração de urânio. 


\section{Abstract}

This article aims to use the content analysis to discuss the public communication stated by the 'Espaço INB', an information center managed by Indústrias Nucleares do Brasil located in the city of Caetité - BA, where the company mines and processes uranium. Since INB started its activities in Caetité, several suspicions of environmental damage and public health problems emerged. Thus, we analyze how INB responds to these suspicions and relates to the populations affected by its activities. We argue that INB adopts an attitude that we call techno-enthusiastic and technocratic, hindering an open public and decentralized debate about the controversies surrounding uranium mining.

Keywords: Science, technology and society; Environmental conflicts; Public participation in science and technology; Public communication; Uranium mining.

\section{Resumen}

El objetivo de este artículo es discutir, a través del análisis de contenido, la comunicación pública transmitida por el 'Espaço INB', un centro de información administrado por Indústrias Nucleares do Brasil ubicado en la ciudad de Caetité/Bahia, donde la empresa hace la mínería y el procesamiento del uranio. Desde que comenzaron, estas actividades han generado numerosas sospechas de daños ambientales y problemas de salud pública. Por eso, analizamos como el INB contesta estas sospechas y se relaciona con las poblaciones afectadas por sus actividades. Argumentamos que el INB adopta una actitud que llamamos tecno-entusiasta y tecnocrática, lo que dificulta un debate público abierto y descentralizado sobre las controversias respecto a la minería de uranio.

Palabras clave: Ciencia, tecnología y sociedad; Conflictos ambientales; Participación pública en ciencia y tecnología; Comunicación pública; Minería de uranio.

Este artigo pertence ao dossiê Comunicação e Meio Ambiente.

Contribuição dos autores: texto integralmente redigido pelo autor.

Declaração de conflito de interesses: não há.

Fontes de financiamento: Fundação de Amparo à Pesquisa do Estado de Minas Gerais (Fapemig) através do Programa de Capacitação de Recursos Humanos (PCRH).

Agradecimentos/Contribuições adicionais: agradeço ao professor Tiago Ribeiro Duarte e aos colegas dos grupos Ciências, Tecnologias e públicos (CTP/UnB) e Inovação, Cidadania e Tecnociência (InCiTe/UFMG). Sou grato ainda à equipe de comunicação das Indústrias Nucleares do Brasil em Caetité/BA pela solicitude durante as visitas ao 'Espaço INB' e à Unidade de Concentrado de Urânio.

Histórico do artigo: submetido: 10 fev. 2020 | aceito: 20 abr. 2020 | publicado: 30 jun. 2020.

Apresentação anterior: não houve.

Licença CC BY-NC atribuição não comercial. Com essa licença é permitido acessar, baixar (download), copiar, imprimir, compartilhar, reutilizar e distribuir os artigos, desde que para uso não comercial e com a citação da fonte, conferindo os devidos créditos de autoria e menção à Reciis. Nesses casos, nenhuma permissão é necessária por parte dos autores ou dos editores. 


\section{Introdução}

A energia proveniente do urânio representa apenas 1,4\% de toda a oferta interna de energia no Brasil, conforme dados do Relatório Síntese do Balanço Energético Nacional de 20181, elaborado pela Empresa de Pesquisa Energética (EPE), empresa pública voltada para a condução de pesquisas destinadas ao planejamento das políticas do setor energético brasileiro. Inúmeras são as defesas do aumento da utilização do mineral para a geração de energia no país. Embora seja proveniente de uma fonte não renovável, a energia nuclear é considerada limpa por alguns especialistas por não produzir gases de efeito estufa. Do ponto de vista de seus defensores, em grande medida a recusa ou os receios diante da energia nuclear devem-se à falta de informações por parte da população brasileira. Pelo menos desde o desastre de Chernobyl e o acidente radiológico com césio-137 em Goiânia, a opinião pública brasileira teria se tornado mais indisposta em relação à energia nuclear. Essa tendência, contudo, poderia ser alterada por meio da utilização de estratégias, como campanhas de divulgação, visitas educativas e mudanças nos modos de comunicação pública voltadas para o esclarecimento da população sobre os riscos nucleares ${ }^{2,3}$. Posicionamentos como estes claramente se aproximam do que se convencionou chamar de modelo de 'déficit' nas estratégias de comunicação pública da ciência. Conforme esse modelo, o público leigo apresenta uma deficiência de conhecimentos em relação a cientistas e especialistas, cujos saberes especializados, quando comunicados satisfatoriamente, são capazes de esclarecer e modificar as atitudes individuais ${ }^{4,5}$. Tradicionalmente, tal modelo associa-se a regimes tecnocráticos de gestão e tomada de decisões.

Por outro lado, pesquisadores, movimentos sociais e ambientalistas têm se mobilizado contrariamente à energia nuclear no Brasil e no mundo, com base sobretudo nas possíveis falhas de segurança e nos riscos de vazamento de materiais radioativos nas usinas (que se elevam à medida que os reatores envelhecem), de contaminação ambiental pelos rejeitos que sobram depois da reação envolvendo o urânio, de ataques terroristas e militares às usinas e na possibilidade de fabricação de armas nucleares a partir do restante do combustível já utilizado na produção energética, como o plutônio ${ }^{6}$. Não por acaso, a Alemanha anunciou, depois do desastre de Fukushima (que evidenciou os riscos atômicos e que "a energia nuclear não pode ser controlada 100\%”, conforme os dizeres da ministra de Meio Ambiente alemã), que pretende desligar todas as suas usinas nucleares até $2022^{7}$.

No Brasil, os processos de mineração e beneficiamento do urânio que é utilizado como combustível nuclear nas usinas de Angra dos Reis-RJ se dão sob responsabilidade das Indústrias Nucleares do Brasil (INB), uma empresa estatal de economia mista atrelada ao Ministério de Minas e Energia. Tais atividades tiveram início em 1999 em Caetité, município do sudeste baiano de aproximadamente 52 mil habitantes ${ }^{8}$. Desde então, a cidade e seu entorno são palco de inúmeras disputas que envolvem a INB e as populações atingidas pela mineração de urânio, posto que essas partes discordam quanto às causas dos problemas ambientais (por exemplo, a contaminação dos recursos hídricos locais) e de saúde pública (como a incidência anormal de câncer entre os habitantes) que acometem a região. O objetivo deste artigo é discutir essas controvérsias a partir, especificamente, dos modos de comunicação pública adotadas pela INB ao tratar dessas questões ambientais e de saúde pública. Para isso, investigamos, através da metodologia de pesquisa de análise de conteúdo", as estratégias discursivo-argumentativas praticadas pela empresa no 'Espaço INB de Ciência, Tecnologia e Cultura', um museu de história regional e de divulgação científica mantido pela própria INB em Caetité. Argumentamos que a postura tecnocrática assumida pela instituição dificulta a efetiva compreensão de riscos ambientais e de saúde pública, além de impossibilitar um debate informado e horizontalizado entre a INB e a população local. Acreditamos que a análise das relações e dos modos de comunicação utilizados entre a INB e seus públicos pode contribuir, primeiramente, para a investigação de outros casos que envolvem conflitos ambientais em razão de empreendimentos econômicos e, em segundo lugar, para a reflexão sobre as posturas tecnocráticas em situações de controvérsias sociotécnicas. 


\section{Os efeitos da mineração de urânio em Caetité}

É possível notar os efeitos da mineração de urânio em Caetité em pelo menos duas dimensões que estão fortemente entrelaçadas: a da saúde pública e a da contaminação ambiental. Essas dimensões ficam evidentes a partir dos dados levantados por dois relatórios, o "Relatório da Missão Caetité: Violações de Direitos Humanos no Ciclo do Nuclear"10, produzido em 2011 por Marijane Lisboa, José Zagallo e Cecília Mello para a Plataforma Dhesca (Direitos Humanos Econômicos, Sociais, Culturais e Ambientais), e o relatório preliminar "Justiça ambiental e mineração de urânio em Caetité/BA: avaliação crítica da gestão ambiental e dos impactos à saúde da população"11, confeccionado por Marcelo Porto, Renan Finamore e Bruno Chareyron por meio de uma parceria entre a Fundação Oswaldo Cruz (Fiocruz) e o laboratório francês Commission de Recherche et d'Information Indépendantessur la RADioactivité (CRIIRAD).

Em primeiro lugar, no que diz respeito à saúde pública, haveria um aumento dos casos de câncer entre os moradores da região, o que em alguma medida seria abertamente reconhecido pelas autoridades locais e pelo governo baiano através do anúncio da construção, na cidade, de um hospital oncológico para casos de alta complexidade. Já em 2012, Maria Alcina Romero, então diretora de atenção especializada da Secretaria de Saúde do Estado da Bahia, admitia que "o câncer tem um comportamento diferente nessa região [a microrregião de Guanambi, onde se localiza Caetitée”, já que ali o número de novos casos é bem superior se comparado ao de outras regiões da Bahia ${ }^{12}$. A precocidade dos casos de câncer é outro aspecto que chama a atenção de médicos que atuam na cidade. O problema é que, em razão da falta de uma base de dados produzida antes da atuação da INB em Caetité sobre a incidência de cânceres e neoplasias na população local, é impossível realizar uma comparação entre a situação de saúde pública anterior e a atual na cidade e, consequentemente, traçar uma possível relação entre a mineração de urânio e a emergência de casos de câncer ${ }^{10}$. A essa dificuldade soma-se o fato de que há um empecilho para a constituição de um quadro fidedigno de saúde pública e de registro de óbitos dos moradores da região, pois, quando diagnosticados com neoplasias, muitos deles buscam tratamento em outros municípios, como Vitória da Conquista. Caso haja morte, a notificação é feita no município em que o paciente procurou tratamento. De todo modo, mesmo que esses dados estivessem disponíveis de modo mais claro e preciso, isso não necessariamente produziria conclusões confiáveis, pois o estabelecimento de 'nexos causais' ou 'epidemiológicos' (entendidos no campo da saúde pública como a associação, fundamentada em dados empíricos, entre uma doença e a exposição a certos riscos) é difícil de ser realizado e comumente gera resultados inconclusivos. Isso se deve ao fato de que "muitos problemas de saúde potencialmente relacionados aos riscos ambientais e/ou ocupacionais possuem inúmeras etiologias, e são raras as doenças cuja causa é exclusivamente atribuída a algum risco ambiental específico" ${ }^{\prime 3}$. Via de regra, essas relações de causalidade são traçadas exclusivamente por especialistas ou, mais raramente, utilizando métodos, como a 'epidemiologia popular', que envolvem a participação das populações expostas. Ainda que não seja possível comprovar que a incidência excepcional de câncer em Caetité esteja relacionada à mineração de urânio, inúmeras são as denúncias de acidentes ocorridos na Unidade de Concentrado de Urânio (URA), onde o mineral é extraído e beneficiado, e de contaminações do ar e da água ${ }^{10,11}$.

Quanto à situação da água, os debates sobre a contaminação dos recursos hídricos ganharam relevância a partir de 2008, quando foi divulgado pelo Greenpeace um relatório que atesta que, ao menos, duas amostras coletadas em locais em que há consumo humano do líquido apresentavam contaminação por urânio muito acima dos limites estabelecidos pela Organização Mundial de Saúde (OMS) e pela legislação brasileira $^{10,14}$. Após a publicação do relatório do Greenpeace, outro estudo de 2008, desta vez solicitado pelo Instituto de Gestão das Águas e Clima (Ingá - BA) e pela Secretaria de Saúde do Estado da Bahia (Sesab) ao Centro de Pesquisa e Desenvolvimento da Universidade Estadual da Bahia (Ceped/Uneb), apontou a presença de radioatividade acima dos limites, estabelecidos pela Portaria do Ministério da Saúde, na água coletada em cinco locais de três municípios. Em janeiro de 2010, outro levantamento do Ingá e da 
Sesab detectou mais três pontos com a presença de radioatividade na água acima do permitido. Como consequência desses estudos, ambas as instituições notificaram as prefeituras de Caetité, Lagoa Real e Livramento de Nossa Senhora para que suspendessem a utilização das águas dos poços e fontes superficiais em que foram identificadas contaminações. Em resposta, a Comissão Nacional de Energia Nuclear (CNEN) - responsável, entre outras atribuições, por regular e fiscalizar atividades do setor nuclear - divulgou uma nota em março de 2010 que não só isentava as atividades da INB pela radioatividade na água (que, de acordo com a nota, teria causas naturais) como também questionava as normas do Ministério da Saúde que estipulavam o máximo de radiação tolerável na água ${ }^{10}$.

As discussões foram novamente acesas em 2015, quando se tornaram públicas as análises da própria INB que indicaram que a água de um dos poços da região era imprópria para o consumo devido à alta concentração de urânio. Trata-se de um poço localizado no sítio do Sr. Osvaldo Antônio de Jesus, que, embora esteja fora da área de influência da URA, foi monitorado pela INB a pedido do proprietário. Os resultados da análise da água foram divulgados pelo jornal O Estado de S.Paulo ${ }^{15}$, o que inflamou um intenso debate sobre o tema. De acordo com a INB, a contaminação não guarda qualquer relação com as atividades desempenhadas pela empresa na região, pois a sub-bacia hidrográfica da localidade em que se encontra o poço contaminado é distinta da sub-bacia onde se situa a URA ${ }^{16}$. Além disso, a INB afirma que a contaminação é natural e anterior à sua atuação, posto que a região é rica em "rochas mineralizadas em urânio" ${ }^{\prime 1718}$. A empresa reforça ainda que possuiu licenciamento ambiental emitido pelo Ibama e nuclear concedido pela CNEN.

Neste ponto está colocada uma das principais controvérsias que perpassam a atuação da INB em Caetité: se as contaminações são naturais ou artificiais. De fato, há uma intensa discordância sobre a presença anômala do urânio no solo e nas águas da região. De um lado, a CNEN, além de outras análises técnicas, defende que essa anomalia decorre da presença natural do urânio na localidade e que, portanto, as atividades da INB não têm qualquer responsabilidade pela contaminação ambiental. Por outro lado, relatórios como o do Greenpeace indicam uma relação direta entre a mineração e a contaminação do solo e da água, o que sugeriria ainda uma relação entre essas condições e a incidência incomum do câncer na região. Contudo, o 'nexo causal' entre a contaminação e os casos câncer não pode ser sustentado na medida em que, como foi ressaltado, não há uma base de dados anterior à atuação da INB sobre o adoecimento por câncer na população local ${ }^{10}$. Diante desse cenário de grande incerteza, interessa-nos compreender como a empresa aborda, por meio de sua comunicação institucional, as controvérsias em torno de suas atividades. Para isso, tomamos como foco, especificamente, o 'Espaço INB', um centro de informações gerido pela empresa em Caetité.

\section{O 'Espaço INB'}

O 'Espaço INB de Ciência, Tecnologia e Cultura' tem localização privilegiada, disposto num dos lados da praça principal de Caetité, atrás da Catedral de Senhora Sant'Ana, num casarão antigo restaurado pela própria mineradora. Quando ali chegamos para uma primeira visita, numa tarde do final de julho de 2019, encontramos o Espaço com as portas internas fechadas. Fomos recebidos, depois de soar a campainha, por um pessoal solícito e bem preparado, que se encarregaria de guiar a visitação. A condução da visita, que se deu individualmente, se resumiu à obediência a um roteiro previamente ensaiado.

O itinerário tem início com uma exposição permanente sobre a história de Caetité: por exemplo, a importância do município na região e registros de edifícios antigos já demolidos - que se contrapõem às iniciativas da INB, tal como ressaltadas durante a visita, de preservar a história local, bem como de restaurar parte de seu casario, como o próprio sobrado que abriga o Espaço. A visitação prossegue através de outra exposição permanente, agora mais focada no urânio, sua história, mineração, beneficiamento e 
a produção de energia nuclear. Há dados sobre a história e a descoberta do urânio, informações sobre as distintas fontes de energia (eólica, solar, fóssil, nuclear etc.) e, inclusive, a exibição de uma amostra de minério de urânio proveniente da mina Cachoeira, acompanhada da seguinte inscrição: "minério de urânio (incipientemente mineralizado, levemente radioativo)”. Em seguida, em totens que giram, de algum modo interativos, são apresentados dados sobre a descoberta das reservas de urânio brasileiras (com ênfase à Província Uranífera de Lagoa Real, que abarca Caetité) e sobre as atividades da INB na região. Num dos painéis, intitulado ‘Caetité, o Brasil e o Mundo', lemos que “o Instituto Brasileiro do Meio Ambiente e dos Recursos Naturais Renováveis (IBAMA), a Comissão Nacional de Energia Nuclear (CNEN) e a Agência Internacional de Energia Atômica (AIEA) atestam que as atividades de mineração e beneficiamento da INB Caetité são eficientes, seguras

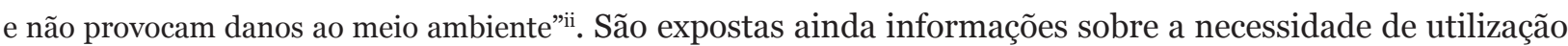
de energia nuclear, bem como sobre sua eficiência (por exemplo, no totem denominado 'Equivalência energética', encontramos ilustrações acompanhadas da comparação de que $1 \mathrm{~kg}$ de urânio natural produz energia equivalente a 10 toneladas de petróleo ou a 20 toneladas de carvão). Na sala que sucede à que apresenta os totens, há monitores de televisão que exibem, cada um, vídeos explicativos sobre cada etapa do ciclo do combustível nuclear para, em seguida, o público ser conduzido a duas réplicas um tanto atraentes: uma das varetas que compõem o elemento combustível e outra do núcleo do reator utilizado em uma das usinas de Angra dos Reis/RJ. A visita termina com demonstrações das iniciativas de conservação e recuperação ambiental desenvolvidas pela INB. Na 'Sala Exsicatas', há uma exibição de amostras de plantas nativas secas e prensadas, devidamente catalogadas pela equipe do Horto da empresa, a qual, aliás, também desenvolve técnicas experimentais para a quebra de dormência de sementes de vegetais da região. O Espaço conta ainda com outra exposição permanente, intitulada 'Riquezas minerais da Bahia', voltada para a apresentação dos diversos minerais presentes no estado baiano, o local em que são encontrados e sua utilidade. Para além de todas essas seções temáticas com o acervo permanente, o Espaço abrigava também, nos dias em que estivemos na cidade, a exposição temporária 'Caetité, um lugar, vários olhares', que exibia fotografias tiradas por moradores da cidade depois de oficinas oferecidas pela INB ${ }^{19}$.

Concluída a visita, não são fornecidos os créditos referentes às exposições permanentes. Tampouco há fontes junto aos dados disponibilizados (como os relativos à história do urânio ou à proporção da matriz nuclear na produção energética mundial). Além disso, algumas informações que parecem desatualizadas ou equivocadas nas legendas explicativas são corrigidas através da colagem de pequenas folhas de papel sobre as inscrições previamente plotadas e dispostas nas paredes. É o caso, por exemplo, da fotografia de uma cientista indevidamente associada à Marie Curie, cujo nome foi subtraído por meio de um recorte de papel. Retificações foram feitas também no painel que apresenta um mapa-múndi com o número de usinas nucleares presentes em cada país. Diante desse painel, o roteiro da visita guiada prevê uma comparação: a França, com território tão pequeno, possui inúmeras usinas nucleares, enquanto o Brasil, tão extenso, tem apenas duas. Claramente, há a sugestão de que certo gigantismo brasileiro é atrasado ou mal aproveitado em decorrência da pouca utilização da energia nuclear, associada a países ricos e desenvolvidos.

\section{"Eu não sabia que era assim...": a INB e seus públicos}

De modo geral, o Espaço parece operar a partir de duas lógicas. A primeira é a de 'déficit', atrelada a uma visão que concebe a comunicação pública da ciência como um ato de 'popularização' e de 'informação', o que depende da tradução de noções complexas numa linguagem simples e acessível a um público tido como homogêneo e passivo. Nessa perspectiva, "os grupos públicos são frequentemente retratados como sendo

\footnotetext{
i Frase transcrita de materiais do acervo do Espaço INB.
}

ii Frase transcrita de materiais do acervo do Espaço INB. 
ignorantes e irracionais em relação ao progresso científico. Presume-se que a crítica externa da ciência [...] implica uma falta de conhecimento público em vez da necessidade de reflexão sobre a ciência e auto-apreciação" ${ }^{\text {"o }}$.

Em geral, tal modelo, dominante até a década de 90, entende a ciência como uma esfera apartada da sociedade, além de considerar que entre elas é estabelecida uma relação assimétrica - a ciência pode facilmente influenciar a sociedade (através da aplicação de tecnologias, por exemplo), mas a sociedade dificilmente interfere na atividade científica. Por essa razão, as informações são transmitidas de modo unidirecional e 'de cima para baixo', dos cientistas para o público5. Na mesma linha, Massimiano Bucchi ${ }^{4}$ indica que a lógica de 'déficit' reage à opinião pública com base em duas concepções: 1) as pessoas são mal informadas sobre ciência e, em razão disso, 2) elas podem facilmente adotar comportamentos irracionais e hostis ao desenvolvimento científico e tecnológico. É preciso, então, garantir que temas complexos sejam tratados por pessoas verdadeiramente qualificadas, os especialistas, ou, alternativamente, buscar iniciativas de médio e longo prazo que diminua a distância entre os experts e público comum, a fim de compensar o 'déficit' que caracteriza o público 'leigo'. "A solução parece simples: será suficiente comunicar mais e melhor os resultados de pesquisas científicas. Assim, o público será mais bem informado e, consequentemente, adotará os pontos de vista da comunidade científica"4.

Daí surge a utopia de transformar pessoas quaisquer em especialistas em ciência, um projeto que toma como segura a seguinte cadeia causal: "mais comunicação = mais discernimento = mais apoio à ciência = mais inovação = mais desenvolvimento econômico" 4 . O problema é, como ressalva Bucchi, que essa causalidade é problemática por várias razões. Para citar apenas alguns equívocos, não há evidências de que mais comunicação e mais informações científicas mudem a visão de mundo e as atitudes dos espectadores. Além disso, é possível que o público deliberadamente escolha não se inteirar de determinados assuntos ou simplesmente ignore dados técnicos que não lhes parecem úteis ou confiáveis. Por último, dificilmente seria possível qualificar satisfatoriamente as pessoas em várias áreas, posto que isso não ocorre nem entre os cientistas, que tendem a ser especialistas em seus campos e ignorantes em outros ${ }^{4}$.

É curioso que todo esse treinamento pedagógico dos públicos não necessariamente acalmou ou diminuiu os dissensos e as controvérsias diante da ciência e tecnologia. Todavia, mesmo equivocado, esse modelo 'paternalista' e 'missionário' perdurou (e perdura, como nos parece ser o caso de Caetité) por um bom tempo. Pelo menos dois fatores explicariam essa longevidade. O primeiro deles tem a ver com o estatuto especial conferido ao discurso científico, tido como 'objetivo' e comprometido com a 'verdade', o que facilita sua divulgação e possível aceitação pelas pessoas. O segundo fator refere-se ao fato de que os cientistas tendem a entender as questões públicas relativas à ciência como problemas sociais, exteriores ao âmbito científico, e não como decorrentes de falhas e incertezas que circulam entre os próprios especialistas. Neste sentido, o que deve mudar é a sociedade, não a ciência ${ }^{4}$. Naturalmente, o modelo de 'déficit' deposita grande confiança na ciência como promotora do progresso e a entende como uma atividade autorregulada, em que os experts devem, sem as perturbações do Estado, do mercado e da sociedade civil, autonomamente desenvolver seus trabalhos ${ }^{21}$. De resto, esta lógica é pensada para contornar "uma ansiedade provocada [nos cientistas] pelo receio de que a ignorância do público interfira no progresso científico/tecnológico”²o.

No 'Espaço INB', o modelo de 'déficit' é sustentado por uma concepção de que ali é trabalhado um tema altamente complexo do qual o público não tem conhecimento. A própria equipe de comunicação aponta como um desafio a dificuldade de comunicar informações complicadas aos visitantes sem recorrer estritamente à terminologia técnica, o que requer, entre outras estratégias, o uso de analogias (por exemplo, a lixiviação é explicada em comparação ao ato de coar café ou o processo de extração do urânio, numa das etapas de beneficiamento, é associada à imagem de um 'ímã químico'). A equipe também ressalta a complexidade do ciclo do combustível nuclear bem como de todas as atividades da INB e relata que várias pessoas trazem questões específicas voltadas para outros ramos de atuação da empresa, distintos da mineração e do beneficiamento do urânio, como os de enriquecimento e montagem do elemento combustível, realizados 
pela INB em Resende/RJ, na Fábrica de Combustível Nuclear (FCN). Em suma, o pessoal da comunicação reforça que a empresa sempre esteve de portas abertas e disposta a dialogar com e a informar a população, mas pondera que é preciso avaliar até que ponto as pessoas estão dispostas a escutar (segundo a equipe, há períodos em que o Espaço recebe mais visitantes de fora de Caetité do que da própria cidade). Depois de concluída a visita guiada, as pessoas costumam ter uma visão positiva da INB. "Eu não sabia que era assim...”é uma reação muito comum entre os que passam pelo Espaço, observa a equipe de comunicação. É significativo, a respeito do pressuposto do ‘déficit', o questionário de avaliação da satisfação do público, que, diante da questão 'a visita foi útil para', fornece as seguintes opções: 'receber primeiras informações sobre o tema; esclarecer dúvidas; aumentar meu interesse sobre os temas'. Todas as alternativas inferem que falta conhecimento especializado aos visitantes, algo a ser compensado com a ida ao Espaço.

A segunda lógica norteadora das atividades do Espaço é a tecnoentusiasta, visto que os traços de autocrítica e reflexividade que perpassam a ciência na contemporaneidade, tal como diagnosticado por Beck $^{22,23}$, Jasanoff ${ }^{21}$, entre outros, parecem ausentes do discurso institucional da INB. Resta, portanto, uma confiança otimista na ciência e na tecnologia, que podem ser utilizadas para fazer 'o bem'. Em geral, a visão tecnoentusiasta está associada ao que Feenberg ${ }^{24,25}$ entende por abordagem instrumentalista na tecnologia, decorrente de certo senso comum moderno que considera a tecnologia, em primeiro lugar, como neutra, isenta de valores, e, em segundo lugar, como algo instrumental, um meio do qual nos valemos para atingir inúmeros fins. Uma coisa não traz em si mesma, em sua 'essência', um significado dado ou os fins a que se destina; somos nós, humanos, que lhe atribuímos um sentido e a utilizamos conforme nossas necessidades (um martelo, suponhamos, pode ser usado como ferramenta para fixar um prego ou como arma para atentar contra uma pessoa).

É precisamente o livre-arbítrio humano que fundamenta a visão 'instrumentalista', cujo grande problema, conforme Feenberg ${ }^{25}$, é que ela leva a uma despolitização da tecnologia, ao promover uma rígida separação entre ciência/tecnologia e política, entre saber e poderiii. Um objeto técnico nunca será bom ou mau, mas depende dos usos que fizermos dele. Ou seja, para o instrumentalismo, a tecnologia se submete a valores que lhe são exteriores, estabelecidos em outras esferas, como a moral, a cultura e a política ${ }^{24}$. Tanto o Iluminismo quanto o Positivismo adotam a ideia da neutralidade da ciência, que seria, de acordo com essas correntes, a grande responsável por conduzir a humanidade ao progresso. De modo tecnoentusiasta, é possível esperar um futuro melhor que o passado, graças à ciência que trará soluções para os diversos problemas, inclusive para os que ela própria eventualmente causar ${ }^{26}$. Por fim, a retórica da neutralidade científica guarda enormes afinidades com a conduta tecnocrática ${ }^{4}$.

Conforme a visão tecnoentusiasta do 'Espaço INB', a energia nuclear é, indubitavelmente, um salto tecnológico e uma condição para o desenvolvimento. De acordo com essa concepção, a energia nuclear é limpa, segura e eficiente, praticamente sem riscos ou efeitos colaterais (os quais, aliás, não foram abordados ao longo da visita guiada ao Espaço). Essa perspectiva é evidenciada em trechos de materiais disponibilizados pela empresa. No folheto 'Urânio: energia da Terra', lemos que "a energia do átomo de urânio [...] libera calor e produz vapor que movimenta as turbinas das usinas nucleares, gerando energia. É energia limpa, que não emite gás carbônico, não contribui para o aquecimento do planeta. É fonte segura, que tem todas as etapas de sua produção fiscalizadas por organizações nacionais e internacionais. Urânio brasileiro - mais energia para o desenvolvimento do País" ${ }^{\prime 2}$. O material esclarece que a energia das centrais nucleares não vem diretamente do átomo de urânio, mas do vapor por ele produzido que, por sua vez, é utilizado para movimentar turbinas das usinas. O processo é descrito de forma a aproximar o modo de operação de uma planta nuclear ao funcionamento de outras usinas termelétricas (o que também é feito durante a visitação guiada ao Espaço).

iii Por meio do conceito de "código técnico", Feenberg ${ }^{24}$, com base em sua teoria crítica da tecnologia, tece críticas bastante apropriadas ao instrumentalismo. Semelhantemente, ao questionar a "ilusão" da neutralidade da tecnociência, Bucchi ${ }^{4}$ conclui que "não existem [...] objetos meramente técnicos, mas híbridos que incorporam uma perspectiva moral e sociopolítica". 
Tal aproximação retira certo caráter de excepcionalidade da energia de matriz nuclear - algo próximo aos processos de "desnuclearização" descritos por Hecht ${ }^{28}$ - e contribui, assim, para mitigar possíveis temores seletivos do público diante do tema. Logo, o texto, mediante essas comparações, argumenta a favor da segurança da energia nuclear, que também é considerada limpa por não fomentar o aquecimento global. Por fim, é curioso o efeito da atribuição de um adjetivo pátrio ao urânio, como se o mineral tivesse uma nacionalidade, ou fosse 'da Terra' (expressão cuja ambivalência semântica é propositalmente utilizada no título do folheto para referir-se tanto à procedência geológica do urânio quanto ao fato de ele ser 'nativo'). Num gesto manifestamente nacionalista e tecnoentusiasta, o urânio brasileiro é atrelado à soberania e ao progresso nacionais. O tom ufanista está presente também no momento da visitação ao Espaço em que é ressaltado o privilégio do Brasil, um dos poucos países do mundo que detém não só a tecnologia de enriquecimento do urânio (embora não tenha a capacidade instalada de enriquecer todo o mineral em território nacional) quanto a própria matéria-prima.

Em outro fôlder, intitulado 'Um universo de tecnologia: combustível nuclear', encontramos, logo na abertura, uma definição de "tecnologia", que é associada à "arte", à "totalidade de conhecimentos". Em seguida, são apresentadas algumas atividades da INB, desenvolvidas em "instalações e equipamentos de última geração, com pessoal técnico altamente especializado", com "rigoroso controle de seus processos e total confiabilidade no resultado final", além de voltadas para o "fornecimento de energia elétrica em larga escala, o que preserva o meio ambiente e garante a qualidade de vida às futuras gerações" ${ }^{29}$. Novamente encontramos uma aproximação entre usinas nucleares e usinas térmicas, que utilizam o mesmo 'princípio básico de funcionamento'. Do mesmo modo, é reforçado que a energia nucleoelétrica é limpa, pois "não emite nenhum gás de efeito estufa", "nenhum gás causador de chuva ácida", "nenhum metal carcinogênico, teratogênico ou mutagênico" nem "libera gases ou partículas que causam poluição urbana ou diminuição da camada de ozônio"29. O caráter de eficiência da energia nuclear é evidenciado a partir da afirmação de que "530 quilos de urânio têm a capacidade para o suprimento de energia elétrica a 42.00o residências médias durante um mês. Para fornecimento a um mesmo número de residências, em igual período, seriam necessárias cerca de 5.200 toneladas de petróleo ou 13.000 toneladas de carvão”29. Por fim, o fôlder apresenta todas as etapas do ciclo do combustível nuclear, da mineração à geração de energia, onde termina, sem prestar qualquer informação sobre a destinação e tratamento dos rejeitos radioativos (lacuna que tampouco é abordada na visita guiada).

Num terceiro fôlder, 'Radiação e o nosso dia a dia', são traçadas comparações entre a radiação emitida pelo urânio em estado natural e outras fontes naturais de radiação, como o sol, a terra, alguns minérios e "até [...] nosso corpo"3o. Conforme o material, da mesma forma como devemos nos proteger da radiação natural (por meio do uso de filtro solar, de chapéus ou evitando a sair ao sol em determinadas horas do dia), a INB controla a exposição de seus trabalhadores à radiação, além de monitorar o meio ambiente e a saúde dos moradores do entorno da mina por meio da avaliação dos níveis de concentração de urânio nas águas, no ar e nos produtos agropecuários. Desse modo, é possível analisar se "as atividades da empresa provocam alguma alteração nos níveis de urânio dentro da INB e nas áreas próximas”30 monitoramento são comparados com os resultados anteriores à operação da mina.

Novamente está colocada a principal controvérsia que perpassa a atuação da INB em Caetité: se as contaminações por urânio e os níveis de radiação identificados na região são naturais ou artificiais. Ao afirmar, através do fôlder, que há "urânio em nosso ambiente porque ele faz parte da nossa natureza" ${ }^{30}$ e ao aproximar a radiação emitida pelo urânio de outras fontes naturais de radiação, a INB não só reafirma o caráter natural das contaminações como reconhece que as mesmas são perigosas e podem trazer riscos à saúde, mas que podem, desde que devidamente identificadas e conhecidas, ser controladas ou amenizadas - através da ocupação consciente do espaço ou da utilização de equipamentos e estratégias de proteção, por exemplo. Schütz, Porto e Silva ${ }^{31}$ identificam aspectos semelhantes no entendimento oficial de "radioatividade" por parte do Estado brasileiro, que a define, através de um glossário disponibilizado 
pelo Ministério de Minas e Energia, como a "desintegração natural de elementos químicos com a emissão de radiações e formação de novos elementos que possuem pesos atômicos menores"31. Os pesquisadores encontram concepções parecidas também em apostilas educativas publicadas pela CNEN. Longe de constituir um entendimento insignificante ou em desuso, essa visão, conforme os autores, é uma "construção simbólica hegemônica em setores científicos e oficiais brasileiros, empenhada em naturalizar a radiação ionizante enquanto parte de uma estratégia de comunicação de risco"3¹.

Assim, o posicionamento da INB, alinhado a essa 'construção simbólica hegemônica', sugere três características da radiação e, em parte, das contaminações ambientais: 1) são inexoráveis, já que desde o sol até os nossos ossos e tecidos são compostos por elementos radioativos; 2) são onipresentes, pois a radiação “está em toda parte", conforme o folheto ${ }^{30}$ : nas rochas, embaixo da terra, nas águas, no espaço cósmico; 3) são de algum modo equivalentes, pois não há, a partir da comunicação pública da empresa, uma clara distinção entre a radiação natural e a proveniente do urânio concentrado, entre os riscos de radiação solar e os decorrentes das atividades da INB, ou mesmo entre a energia nuclear e outras formas de geração de energia. Essas insinuações são problemáticas, pois a indistinção entre o antes e o depois da ação antrópica em lugares naturalmente radioativos pode negligenciar aspectos relevantes para o planejamento da gestão ambiental e da saúde de trabalhadores e comunidades atingidos ${ }^{31, i v}$. Além disso, "ocultar a diferença entre um cenário de exposição ambiental à radiação natural e outro em que foi introduzido um processo produtivo de mineração pode resultar conveniente aos interesses da indústria nuclear, mas não contribui para a correta avaliação, prevenção, gerenciamento e comunicação de riscos" ${ }^{\prime 1}$.

O roteiro de visitação, o acervo permanente do Espaço, bem como os materiais explicativos ali distribuídos, demonstram, de algum modo, operar numa postura defensiva, através da antecipação e do apaziguamento de críticas, dissensos e controvérsias. Tal conduta está alinhada às lógicas de 'déficit' e de tecnoentusiasmo. De acordo com a INB, não há riscos ou danos ambientais, pois a região de Caetité já é naturalmente contaminada e, mais do que isso, a radiação possui um caráter de inexorabilidade e onipresença, conforme nossas interpretações. Tampouco há qualquer ameaça à saúde provocada pela atuação da INB, pois a população, desinformada, já ocupava áreas inapropriadas e consumia água e alimentos com chances de estarem contaminados antes das operações da URA. Por fim, não há problematizações a serem direcionadas à energia nuclear, já que, além de parecida com outras fontes termelétricas, ela é limpa, segura e eficiente.

\section{Considerações finais}

A partir da análise dos materiais e das estratégias de comunicação pública adotados pela INB, parece-nos que o Espaço e a empresa, de maneira geral, ao invés de estabelecerem um diálogo crítico com a população local, adotam um raciocínio e uma estratégia reducionistas e monolíticos, blindados a qualquer tipo de questionamento e negacionista em relação aos riscos seja da mineração e do beneficiamento de urânio, seja da energia nuclear. Neste sentido, ao invés de dialógicas, as práticas da empresa, por meio de seus canais de comunicação, tratariam de convencer e persuadir os moradores quanto à segurança e a qualidade dos trabalhos por ela desenvolvidos. Dessa forma, são reduzidos os receios e incertezas da população e, consequentemente, sufocadas as controvérsias e modos de participação por ela possivelmente suscitados. Além de tecnoentusiasta, encontramos, portanto, um modelo tecnocrático de relação entre especialistas e público, em que os primeiros 'iluminam' (e silenciam) os segundos. Algo semelhante é identificado por Irwin $^{20} \mathrm{em}$ seus estudos sobre as relações entre cientistas e cidadãos diante das incertezas envolvidas nos

iv A estratégia de "naturalizar" os riscos radioativos é semelhante à de negar o estatuto de "nuclear" ao urânio proveniente de países pobres ${ }^{28}$, já que ambas podem resultar em descuido com os processos de regulação e fiscalização da mineração e do beneficiamento desse mineral. 
casos relativos à utilização do herbicida 2,4,5-T, suspeito de causar sérios danos à saúde de trabalhadores e ao meio ambiente, e à ocorrência de 'vaca louca' em bovinos da Inglaterra. O que se verifica, em ambos os casos, é "uma luta entre cientistas armados com 'os fatos' e um grupo irracional de cidadãos” ${ }^{\text {”o }}$. Isso nos remete ainda à concepção da ciência, e de seus experimentos, como um artifício por meio do qual é possível, por um lado, levar os fenômenos a falarem por si próprios, sem a interferência dos cientistas, e, por outro lado, 'fazer calar' os adversários incrédulos, tanto da própria comunidade científica quanto do público em geral ${ }^{32}$. Em suma, a tecnocracia se constitui enquanto uma maneira eficiente de encerrar controvérsias e aquietar os públicos na medida em que opera a partir de dois movimentos complementares: o de despolitização da técnica e o de tecnicização da política.

Por fim, acreditamos que essa postura é especialmente indesejada no caso de um contexto de absoluta incerteza, como o de Caetité, em que não é possível verificar as causas das contaminações, e do ciclo do combustível nuclear, cujos riscos não estão associados a fenômenos lineares e probabilísticos, passíveis de serem previstos, mas sim a indeterminações típicas de fenômenos complexos ou mesmo à ignorância do próprio conhecimento científico. Por essa razão, insistir num modelo de ciência supostamente capaz de atuar com neutralidade e objetividade pode favorecer a falta de diálogo entre empresas e comunidades, além de suscitar um quadro de vulnerabilidade institucional que dificulta, por exemplo, os processos de regulação, licenciamento e fiscalização ${ }^{31}$. Conforme as estratégias de comunicação utilizadas pela INB, “a ciência em si não constitui problema - o problema está em conseguir a compreensão do público e, logo, a aceitação da ciência”"2o. Para esta concepção, quando há tensões entre a ciência e os cidadãos, isso se deve à irracionalidade dos públicos, e não às falhas e incertezas que a própria ciência pode apresentar. Se as pessoas permanecem preocupadas mesmo depois de terem sido 'informadas' por meio de dados certificados pela ciência, isso só pode ser decorrente de seus comportamentos 'emocionais' e histéricos ${ }^{20}$. Todavia, mais propositivo do que pressupor (e culpabilizar) a ignorância alheia seria promover a apreciação crítica e reflexiva da atividade científica sobre si mesma. Talvez assim seja possível não só elucidar as controvérsias em torno das contaminações em Caetité, mas também fomentar processos de participação pública mais abertos e democráticos.

\section{Referências}

1. Empresa de Pesquisa Energética (BR). Balanço Energético Nacional 2017: relatório síntese [Internet]. Rio de Janeiro: A Empresa; 2018 [citado em 2020 maio 19]. Disponível em: https://bit.ly/3dVyiie.

2. Ferreira VVM, Soares WA. Insucessos em empreendimentos nucleares devido a falhas em processos de Comunicação Pública. Intercom, Rev Bras Ciênc Comun 2012 dez.;35(2):313-29.

3. Kiiper FM. Percepção pública das instalações nucleares [dissertação]. São Paulo: Universidade de São Paulo; 2011.

4. Bucchi M. Beyond technocracy: science, politics and citizens. Heidelberg: Springer Science \& Business Media; 2009.

5. Castelfranchi Y. Scientists to the streets. Science, politics and the public moving towards new osmoses. J Sci Com. 2002 June;1(2):F01.

6. Hirsch $\mathrm{H}$ et al. Perigos dos reatores nucleares: riscos na operação da tecnologia nuclear no século XXI. Estud Av [Internet]. 2007 abr. [citado em 2020 maio 19];21(59):253-57. Disponível em: http://www. scielo.br/scielo.php?script=sci arttext\&pid=S0103-40142007000100020\&lng=en\&nrm=iso.

7. Alemanha fará desligamento de usinas nucleares até 2022. Exame (Editora Abril) [Internet]. 2016 mar. 10 [acesso em 2020 maio 19]:Mundo. Disponível em: https://bit.ly/2LEoPjo.

8. Indústrias Nucleares do Brasil. Onde estamos: Caetité [Internet]. Rio de Janeiro: A Indústria; [ano desconhecido] [acesso em 2020 maio 19]. Disponível em: https://bit.ly/2LEyGpg.

9. Bauer MW. Análise de conteúdo clássica: uma revisão. In: Bauer, Martin, Gaskell, George. Pesquisa qualitativa com texto, imagem e som: um manual prático. Petrópolis: Vozes; 2008. p. 189-217. 
10. Lisboa M, Zagallo J, Mello C. Missão Caetité: violação de direitos humanos no ciclo nuclear. Curitiba: Plataforma DHESCA Brasil; 2011.

11. Porto MFS, Finamore R, Chareyron B. Justiça ambiental e mineração de urânio em Caetité/BA: avaliação crítica da gestão ambiental e dos impactos à saúde da população: relatório preliminar. Rio de Janeiro: ENSP, CRIIRAD, EJOLT; 2014.

12. Borges A. Governo baiano admite maior incidência de câncer em região contaminada por urânio. Estadão (Editora Abril) [Internet]. 2015 set. 29 [acesso em 2020 maio 19]. Disponível em: https://bit. Iy/36IXHiI.

13. Porto MF, Finamore R. Riscos, saúde e justiça ambiental: o protagonismo das populações atingidas na produção de conhecimento. Ciênc Saúde Coletiva [Internet]. 2012 jun. [acesso em 2020 maio 19];17(2):1493-1501. Disponível em: http://www.scielo.br/scielo.php?script=sci arttext\&pid=S1413$\underline{81232012000600013 \& \operatorname{lng}=e n \& n r m=i s o}$.

14. Corrêa A. Produção de urânio contamina água na Bahia, diz Greenpeace. BBC Brasil (BBC) [Internet]. 2008 out. 16 [acesso em 2020 maio 19]. Disponível em: https://www.bbc.com/portuguese/reporterbbc/ story/2008/10/printable/081016 greenpeacedenuncia ac.shtml.

15. Borges A, Sampaio D. Urânio contamina água na Bahia. Estadão (Editora Abril) [Internet]. 2015 ago. 22 [acesso em 2020 maio 19]. Disponível em: https://bit.ly/2WMafwE.

16. Indústrias Nucleares do Brasil. Media Center: Lista: Nota de esclarecimento [Internet]. Rio de Janeiro: A Indústria; 2015 ago. 24 [acesso em 2020 maio 19]. Disponível em: https://bit.ly/3g3qgFX.

17. Indústrias Nucleares do Brasil. Ibama: urânio em águas de poço na Bahia é de origem natural e não tem relação com as atividades da INB [Internet]. Rio de Janeiro: A Indústria; 2016 abr. 07. [acesso em 2020 maio 19]. Disponível em: https://bit.ly/2TmgPYw.

18. Indústrias Nucleares do Brasil. Urânio em água de poço na Bahia é de origem natural. Indústrias Nucleares do Brasil [Internet]. Rio de Janeiro: A Indústria; [data desconhecida] [acesso em 2020 maio 19]. Disponível em: https://bit.ly/3dZVewU.

19. Espaço INB de Ciência, Tecnologia e Cultura [Internet]. Caetité: O Espaço; [data desconhecida] [acesso em 2020 maio 19]. Disponível em: http://espaco.inb.gov.brl.

20. Irwin A. Ciência cidadã: um estudo das pessoas, especialização e desenvolvimento sustentável. Lisboa: Instituto Piaget; 1998.

21. Jasanoff S. Tecnologias da humildade: participação cidadã na governança da ciência. Soc. Estado [Internet]. 2019 maio [acesso em 2020 maio 19];34(2):565-89. Disponível em: http://www.scielo.br/ scielo.php?script=sci arttext\&pid=S0102-69922019000200565\&lng=en\&nrm=iso.

22. Beck U. A reinvenção da política: rumo a uma teoria da modernização reflexiva. In: Beck U, Giddens A, Lash S. Modernização reflexiva: política, tradição e estética na ordem social moderna. São Paulo: Ed. Unesp; 1997. p. 11-71.

23. Beck U. Sociedade de risco: rumo a uma outra modernidade. 2. ed. São Paulo: Editora 34; 2011.

24. Feenberg A. Transforming technology: a critical theory revisited. Nova York: Oxford; 2002.

25. Feenberg A. O que é filosofia da tecnologia? Const Crít Tecnol Sustentabil. [Internet] 2010 [acesso em 2020 maio 19];1(3):39-51. Disponível em: https://bit.ly/3cNt6wH.

26. Dagnino RP. Neutralidade da ciência e determinismo tecnológico: um debate sobre a tecnociência. Campinas: Editora da Unicamp; 2008.

27. Indústrias Nucleares do Brasil. Urânio: energia da Terra. Caetité: A Indústria; [data desconhecida]. 1 folder.

28. Hecht G. An elemental force: uranium production in Africa, and what it means to be nuclear. Bull Atomic Scient. 2012;68(2):22-33.

29. Indústrias Nucleares do Brasil. Um universo de tecnologia: combustível nuclear. Caetité: A Indústria; [data desconhecida]. 1 folder.

30. Indústrias Nucleares do Brasil. Radiação e o nosso dia a dia. Caetité: A Indústria; [data desconhecida]. 1 folder. 
Reciis - Rev Eletron Comun Inf Inov Saúde. 2020 abr.-jun.;14(2):329-41 | [www.reciis.icict.fiocruz.br] e-ISSN 1981-6278

31. Schütz GE, Porto MFS, Silva RFG. Dilemas da gestão para tecnologias complexas e perigosas: o caso da mineração de urânio. R Bras Ci Tecnol Soc. 2011;2(2):187-212.

32. Stengers I. A invenção das ciências modernas. São Paulo: Ed. 34; 2002. 